Bridging the Gap: Fraction Understanding is Central to Mathematics Achievement in Students from Three Different Continents

Joke Torbeyns ${ }^{1}$, Michael Schneider ${ }^{2}$, Ziqiang Xin $^{3}$, and Robert S. Siegler ${ }^{4,5}$

\author{
${ }^{1} \mathrm{KU}$ Leuven, Belgium \\ ${ }^{2}$ University of Trier, Germany \\ ${ }^{3}$ Central University of Finance and Economics, China \\ ${ }^{4}$ Carnegie Mellon University, U.S. \\ ${ }^{5}$ Beijing Normal University, China
}

Correspondence concerning this article should be addressed to Joke Torbeyns, KU Leuven,

Centre for Instructional Psychology and Technology, Dekenstraat 2, box 3773, 3000 Leuven, Belgium. Tel: +32 163257 18, fax: +32 163262 74, e-mail:

joke.torbeyns@ppw.kuleuven.be 


\section{Bridging the Gap: Fraction Understanding is Central to Mathematics Achievement in Students from Three Different Continents}

\section{Introduction}

Understanding fractions is crucial for mathematics learning: It not only requires a deeper understanding of numbers than is ordinarily gained through experience with whole numbers, it is also predictive for students' mathematical achievement years later (Bailey, Hoard, Nugent, \& Geary, 2012; Booth \& Newton, 2012; Siegler et al., 2012). Despite increasing research interest in the domain of fractions, almost all studies of the role of fraction magnitude understanding in mathematics learning have been conducted in the U.S., limiting the generality of the findings to only U.S. students and adults. This study aims to deepen our understanding of the pivotal role of fraction magnitude understanding for students' general math achievement in three countries on three different continents that differ greatly in cultural and educational practices.

\subsection{The Integrated Theory of Numerical Development}

Our starting point was Siegler, Thompson, and Schneider's (2011) integrated theory of

numerical development. ${ }^{1}$ As discussed there, current theories of numerical development fail to integrate whole numbers and fractions within a single framework (e.g., Geary, 2006; Leslie, Gelman, \& Gallistel, 2008; Wynn, 2002). Although these theories differ in many particulars, they all posit a gap between an early developing, "natural" understanding of whole numbers and a later developing, flawed, limited, or hard-won understanding of fractions. To the extent that relations between whole numbers and fractions are posited, the earlier developing understanding of whole numbers is said to interfere with the later developing understanding of fractions. For instance, according to conceptual change theories (DeWolf \& Vosniadou, this issue; Stafylidou \& Vosniadou, 2004; Vamvakoussi \& Vosniadou, 2010), children form an initial theory of number as counting units before they encounter fractions, and draw heavily 
on this initial understanding of number to make sense of fractions. Children's faulty generalization of understanding of number as counting units interferes with their learning about fractions, a phenomenon often referred to as the "whole number bias" (Ni \& Zhou, 2005).

Siegler et al.'s (2011) integrated theory of numerical development recognizes these important differences between learning of whole numbers and fractions, but also emphasizes a crucial continuity that unites their acquisition -- steadily expanding understanding of the connection between numbers and their magnitudes. Within this perspective, development of understanding of rational numbers involves both a gradual expansion of the range of whole numbers whose magnitudes are understood (from smaller to larger) and a conceptual change from an initial understanding of numbers in terms of characteristic features of whole numbers to a later understanding of rational numbers in terms of a single defining feature, their magnitudes (see $\mathrm{Wu}, 2001,2009$, for a similar argument).

The integrated theory differs from conceptual change theories in two main ways. One is in its recognizing the positive role of whole number magnitude knowledge in learning fractions, as indicated by longitudinal relations between first graders' knowledge of whole number magnitudes and $7^{\text {th }}$ and $8^{\text {th }}$ graders' knowledge of fraction magnitudes and fraction arithmetic, even after statistically controlling for the IQ, working memory, socio-economic status, race, and other relevant variables (Bailey, Siegler, \& Geary, in press). The second main difference between the integrated theory and conceptual change theories of fraction knowledge is that the integrated theory views interference from whole number knowledge as only one of several sources of difficulty in learning fractions. Evidence for this view comes from findings that despite whole number errors, such as $1 / 2+2 / 3=3 / 5$ being common, confusion with other fraction operations, such as the confusion between fraction addition and 
fraction multiplication evident in $1 / 3 * 2 / 3=2 / 3$, can be even more common (Siegler $\&$ Pyke, 2013).

Within this integrated theory, the reason why fractions are more difficult to learn than whole numbers is the same reason why fractions are crucial to numerical development. A fraction is a ratio or division of two whole numbers, numerator and denominator, and is thus considerably more complex than a single whole number. Whole numbers have unique predecessors and successors, but this is not true of fractions. Multiplying a whole number always leads to a larger number and dividing a whole number always leads to a smaller number, but again this is not true of fractions. Thus, generating a mature understanding of rational numbers requires understanding both the one property that all rational numbers share -- that they have magnitudes that can be located and ordered on number lines -- and understanding that other properties that unite whole numbers do not unite rational numbers.

Consistent with this theory, Siegler et al. (2011) found strong relations between U.S. $6^{\text {th }}$ and $8^{\text {th }}$ graders' fraction magnitude understanding and their general mathematics achievement, even when their mutual relation to fraction arithmetic was statistically controlled. However, these and other data on this topic were collected almost exclusively in the U.S. It thus remains an open question whether the findings are due to the proposed general cognitive learning mechanisms of the theory or to specific properties of the U.S. cultural and educational system (e.g., cultural beliefs about mathematics, teacher training, time spent on mathematics, mathematics curricula).

\subsection{Previous Studies on Fraction Understanding}

Although research interest in students' acquisition of fraction knowledge and skill has increased in recent years, such studies are still far less numerous than studies of whole number understanding. However, the limited number of studies of fractions and the much larger number of studies of whole numbers have revealed highly similar relations among 
magnitude understanding, arithmetic and general mathematics achievement (Siegler, Fazio, Bailey, \& Zhou, 2013).

The same types of behavioural methods have proved useful for investigating fraction as whole number magnitudes: magnitude comparison tasks, in which participants compare the magnitudes of two whole numbers or fractions and indicate the larger one, and number line estimation tasks, in which participants indicate the position of a given whole number or fraction on an empty number line with clearly indicated start and end point. Studies using these methods have consistently revealed that, as with whole number magnitude representations, the precision of fraction magnitude representations differs greatly between and within individuals, depending on students' (instructional) experiences with fractions and the size of the fractions (Siegler et al., 2011; Siegler \& Pyke, 2013). Also as with whole numbers, fraction magnitude understanding has proved to be quite strongly correlated with other aspects of mathematics learning. On top of this correlational evidence, recent investigations provide evidence for predictive relations between earlier fraction magnitude understanding and subsequent knowledge of fraction arithmetic, algebra and overall math achievement (Bailey et al., 2012; Booth \& Newton, 2012; Siegler et al., 2012). To cite one example, Siegler et al. (2012) demonstrated that $5^{\text {th }}$ graders' fraction knowledge predicts their mastery of algebra and overall mathematics achievement in high school, 5 or 6 years later, even after controlling for IQ, reading achievement, working memory, family income and education, and whole number knowledge. The same relations were found in both U.K. and U.S. longitudinal samples. Moreover, Fuchs and colleagues (2013) demonstrated that instruction focused on fraction magnitude understanding improved not only understanding of fraction magnitudes but also fraction arithmetic proficiency among children with mathematics learning difficulties. Taken together, these results indicate that magnitude representations are as central to knowledge of fractions as to knowledge of whole numbers. 
However, to the best of our knowledge, all previous behavioural studies of the role of fraction magnitude understanding in mathematics learning have been conducted in the U.S. -with the one exception of Siegler et al. (2012), which included both U.S. and U.K. samples. This raises questions about the generality of the findings and (consequently) the applicability of the integrated theory of numerical development to populations in other countries and continents. Differences in instructional methods, curricular devices, teacher expertise, and students' absolute levels of achievement might all limit the generality of the findings that have been viewed as supporting the integrated theory. Therefore, in the present study, we investigated students' fraction understanding in three countries with quite different instructional methods and teaching practices: Belgium (Flanders), China, and the U.S.

\subsection{Differences in Teacher Knowledge and Instructional Practices in Mathematics}

International investigations of (prospective) teachers' knowledge, instructional practices and student performances in the domain of mathematics not only document country-specific differences in (prospective) teachers' knowledge and instructional practices, but also stress the importance of these variables for students' mathematical development. Systematic studies in Europe and North America point to deficits in (prospective) teachers' content and pedagogical content knowledge of mathematics in general and rational numbers in particular (e.g., Ball, 1990; Hill, Rowan, \& Ball, 2005; Krauss et al., 2008; Merenluoto \& Lehtinen, 2002; Senk et al., 2012). For instance, most U.S. elementary school teachers participating in the study of Ball (1990) could correctly solve a fraction division task, but they had serious conceptual difficulties in understanding the meaning of the algorithm for division of fractions and in generating an appropriate representation for a division of fraction task. Likewise, the seminal interview study of Ma (1999) on Chinese and U.S. teachers' mathematical knowledge revealed large differences in mathematical content and pedagogical knowledge of teachers in the two countries, including their understanding and teaching of fractions. Recent studies on 
Belgian (Flanders) prospective teachers' content and pedagogical content knowledge of rational numbers and other areas of mathematics also demonstrated weaknesses in these students' knowledge of mathematical content and pedagogy (Depaepe et al., 2013;

Verschaffel, Janssens, \& Janssen, 2005). Since teachers' mathematical knowledge is crucial for both instructional quality and student achievement (Hattie, 2009), country-specific differences in the quality of the mathematics lessons and in students' math performances can be expected.

Findings from the most recent TIMSS (Trends in International Mathematics and Science Study; Mullis, Martin, \& Foy, 2008; Mullis, Martin, Foy, \& Arora, 2012) also revealed a number of cultural differences relevant to mathematics teaching and learning. The participating countries, including Belgium (Flanders), China and the U.S., differed not only in teacher training, experience, and career satisfaction, but also in the amount and quality of mathematics instruction at school, and in students' mathematical experiences outside of school. Moreover, these cultural and instructional differences were strongly related to $4^{\text {th }}$ and $8^{\text {th }}$ graders' performances in the domain of mathematics. Although the TIMSS did not specifically focus on fraction understanding, these cultural and educational differences seem likely to influence learning of fractions as well as other areas of mathematics. Many of the same national differences have been documented in smaller, experimental studies on mathematics knowledge in China and the U.S. and in other international comparisons (e.g., Stevenson \& Stigler, 1992).

Thus, international comparisons of (prospective) teachers' mathematics knowledge and instructional approaches demonstrate clear differences among countries, including Belgium, China, and the U.S. These educational and instructional differences appear to impact students' mathematical development. Cross-cultural performance differences in the domain of mathematics in general were observed in, for instance, the most recent TIMSS (Mullis et al., 
2008, 2012): Of the 29 East Asian, European, and North American countries that participated in the 2011 Grade 4 TIMSS, Chinese students ranked $4^{\text {th }}$, Belgian students $7^{\text {th }}$, and U.S. students $11^{\text {th }}$. Of the 18 North American, East Asian, and European countries in the Grade 8 TIMSS, Chinese students ranked $3^{\text {rd }}$ and U.S. students $9^{\text {th }}$ (no information was available for Belgian students in grade 8). Such performance differences in the domain of mathematics in general and the domain of fractions in particular have been observed in other international comparisons as well (e.g., Wang \& Lin, 2009).

\subsection{The Present Study}

To test the generality of the major assumption of the integrated theory of numerical development, namely that fraction magnitude understanding is crucial to overall mathematics learning, we selected three countries that are known to differ in teachers' knowledge, instructional practices and students' performances in the domain of mathematics, namely Belgium (Flanders), China and the U.S. As documented above, previous work on (prospective) teachers' mathematical knowledge indicated large differences in the knowledge required to effectively teach mathematics between Chinese and U.S. teachers, favouring the former. The mathematical knowledge of Belgian (prospective) teachers appears to be rather limited, closer to that of the U.S. teachers than to that of the Chinese teachers. On the other hand, Belgian and Chinese teachers are similar to each other and different than U.S. teachers in emphasizing magnitude interpretations and using number lines often during fraction instruction.

Based on the results of international comparisons of student achievement and teacher knowledge of mathematics and approaches to teaching mathematics, we hypothesized that Chinese students would perform better than U.S. students on tasks assessing fraction magnitude understanding and fraction arithmetic (= Hypothesis la). We further expected 
Belgian students to perform less well on these tasks than Chinese students (= Hypothesis 1 b); but better than U.S. students (= Hypothesis 1c).

Of greater interest, despite the expected performance differences on the fraction tasks among the participating countries, we did not expect differences among the three countries in the relation between students' fraction magnitude understanding and their general mathematics achievement. Indeed, the integrated theory of numerical development implies that similar relations should be present regardless of the particular educational and cultural system, due to the inherent relations among different types of numbers and the inherent centrality of magnitude understanding to subsequent mathematics learning. We thus formulated our second hypothesis as follows: Not only in the U.S. sample, but also in the Belgian and the Chinese samples, students' fraction magnitude understanding should be strongly related to their general mathematical achievement (= Hypothesis 2).

From many perspectives, our second hypothesis is counterintuitive. Mathematics teachers in China have much deeper fraction knowledge than the ones in the U.S. (and presumably than the ones in Belgium). Hence, they might be able to compensate for differences in the students' magnitude understanding by adapting their instruction to the students' prior knowledge. This would lead to increases in fraction arithmetic skills and math achievement that are largely independent of students' magnitude understanding. Moreover, countryspecific differences in the relation between fraction magnitude understanding and general mathematics achievement might be expected on the basis of differences in fraction instruction. Fraction instruction in the U.S. is almost exclusively based on the part-whole interpretation, whereas students in China and Belgium also encounter substantial emphasis on the measurement interpretation of fractions. From our analyses of the textbooks, it can be concluded that U.S. students are overwhelmingly confronted with the representation and interpretation of fractions as parts of a whole, e.g., as 1 slice of a pizza cut into 4 equal slices. 
By contrast, mathematics textbooks used in Chinese and Belgian classes do not only emphasize part-whole representations and interpretations of fractions, but offer the students substantial experience with measurement representations and interpretations of fractions from the start of fraction instruction, e.g., by including (empty) number lines on which different fractions need to be positioned, ordered and compared in terms of their magnitude. The relation in the U.S. between knowledge of magnitudes, which is at the heart of the measurement interpretation, and mathematics achievement therefore might be present because only students who are particularly good at mathematics develop magnitude knowledge when it is not emphasized in instruction. By contrast, Chinese and Belgian students might not show such a relation, because children in those countries are taught the measurement interpretation, thus reducing the need to induce it.

In the present study, we tested these hypotheses in samples of $6^{\text {th }}$ and $8^{\text {th }}$ grade students from Belgium (Flanders), China and the U.S. Despite differences in culture and educational approaches among the three participating countries, the timing of fraction instruction is highly similar. In all three countries, students are introduced to fractions (beyond the simplest ones, such as $1 / 2$ ) in $2^{\text {nd }}$ or $3^{\text {rd }}$ grade; receive increasingly intensive instruction in fractions, including fraction arithmetic, in $4^{\text {th }}$ through $6^{\text {th }}$ grade; and receive further practice with fractions, embedded in pre-algebra and algebra problems, in later grades. Given the similar timing of fraction instruction in the participating countries, we decided to keep grade rather than chronological age constant across the countries. ${ }^{2}$

\section{Method}

\subsection{Participants}

A sample of 187 students from Belgium (Flanders), China and the U.S. participated to the study. Only students with parental consent were included in the study. Table 1 describes the number of students (boys, girls) and their age (expressed in years) per grade and country. 
-- Insert Table 1 about here --

As shown in Table 1 , the Belgian sample consisted of $306^{\text {th }}$ graders and $348^{\text {th }}$ graders; all were students at a predominantly middle-income school in Flanders, Belgium. The Chinese sample involved $306^{\text {th }}$ graders and $398^{\text {th }}$ graders, coming from a school in Shijiazhuang City, North China's Hebei Province. The U.S. sample included $316^{\text {th }}$ graders (87\% Caucasian, $7 \%$ Indian, 7\% Multiracial) and $238^{\text {th }}$ graders (91\% Caucasian, 4\% African-American, 4\% Middle Eastern), recruited from two predominantly middle-income public school districts near Pittsburgh, PA. We observed no differences in the number of students and in the number of boys and girls in the different samples, all $p s>.05$, but Chinese students were approximately 1 year older than Belgian and U.S. students, $F(2,186)=24.68, p<.01$.

\subsection{Materials}

\subsubsection{Fraction number line estimation}

We used two versions of the number line estimation task that differed only in the numerical range of the line and the presented numbers. The range of the number line was either zero-to-one or zero-to-five. As in past studies, the number line was12 inches (about $31 \mathrm{~cm}$ ) long. It had labels and hatch marks only at the start point (i.e., 0) and the end point (i.e., 1 or 5). On each trial, a different fraction was presented above the middle of the number line. Children were asked to click the mouse on the correct location of the value of the fraction on the number line.

We measured accuracy by computing percentage absolute error (PAE) for each child, computed as $100 *$ abs (estimated value-correct value) / numerical range of the number line. For example, if a student was asked to locate $5 / 2$ on a $0-5$ number line and marked the location corresponding to $3 / 2$, the PAE for that trial would be $100 *$ abs $(1.5-2.5) / 5$ or $20 \%$. (Note that PAE varies inversely with accuracy; the higher the PAE, the less accurate the estimate). In the $0-1$ range, we presented the 29 fractions: 0/1, 1/9, 1/8, 1/7, 1/6, 1/5, 2/9, 1/4, 
$2 / 7,1 / 3,3 / 8,2 / 5,3 / 7,4 / 9,1 / 2,5 / 9,4 / 7,3 / 5,5 / 8,2 / 3,5 / 7,3 / 4,7 / 9,4 / 5,5 / 6,6 / 7,7 / 8,8 / 9$, and

1/1. In the 0-5 range, we presented the 15 fractions: $2 / 9,1 / 2,4 / 7,5 / 3,17 / 9,2 / 1,9 / 4,19 / 8,8 / 3$, $13 / 4,7 / 2,23 / 6,4 / 1,22 / 5$, and 9/2.

\subsubsection{Fraction magnitude comparison}

We presented 12 numerical magnitude comparison trials. On each trial, children saw two fractions next to each other in the middle of an otherwise empty screen. The fraction on the right side was always $3 / 5$. Children had to decide whether the other fraction had a higher or a lower value. They were instructed to enter their answer by clicking at the smaller of the two numbers. We used the fractions $1 / 9,1 / 4,2 / 7,1 / 3,5 / 9,4 / 7,2 / 3,4 / 6,7 / 6,4 / 3,7 / 4$ and $2 / 1$, and scored the percentage of correctly solved trials.

\subsubsection{Fraction arithmetic}

We assessed fraction arithmetic competence by four addition and four division trials. The addition problems were $3 / 6+1 / 6,5 / 2+5 / 3,4 / 7+3 / 8,10 / 3+5 / 11$. The division problems had the same numbers and differed only in the operator. Children were allowed to do calculations on a sheet of paper. They were told that they did not have to reduce their answer to its lowest form, but could do so if they wanted. We scored the percentage of correctly solved trials.

\subsubsection{General math achievement}

We assessed the general math achievement competencies of the participating students using country-specific standardized mathematical achievement tests. For the Belgian sample, we applied two grade-specific Flemish standardized mathematical achievement tests (for $6^{\text {th }}$ graders, LVS Wiskunde Midden 6; Deloof, 2005; for $8^{\text {th }}$ graders, Peiling Wiskunde Eerste Graad A-stroom secundair onderwijs; Gielen et al., 2010); the participating Flemish $6^{\text {th }}$ and $8^{\text {th }}$ graders received above-average scores on these tests, with group mean scores of $M=38$, $S D=12($ maximum score $=59)$ and $M=30.50, S D=3.5$ (maximum score $=39)$, respectively . 
We assessed Chinese students' mathematics proficiency on the basis of their mid-term mathematics examination score. Average mathematics proficiency scores were $M=90.08$ $(S D=6.40)$ for the $6^{\text {th }}$ graders and $M=86.95(S D=10.91)$ for the $8^{\text {th }}$ graders (maximum score $=100$ ). The mathematics proficiency of the U.S. students was administered on the basis of the school-reported PSSA (Pennsylvania System of School Assessment), the standardized test used in the part of the U.S. where the study was performed. Most students, i.e., $71 \%$ of the $6^{\text {th }}$ and $61 \%$ of the $8^{\text {th }}$ graders, scored at or above a proficient level on this state test of mathematics achievement (for $6^{\text {th }}$ graders, $M=1440, S D=179$; for $8^{\text {th }}$ graders, $M=1459, S D=258)$.

\subsection{Design and Procedure}

In each country, children were tested individually for about 30 minutes in a quiet room in their school. The procedure followed was identical in the three participating countries. All measures were presented on a laptop computer with a screen resolution of 1024 x 768 px. The assessment program saved answers in log files, which we used for our analyses. The order of the tasks and the order of the items in each task were randomized for each student. Participants completed all items on one task before being presented any items on the next.

\section{Results}

Results are presented in two parts. We first discuss the results relevant to the expected performance differences among Belgian, Chinese and U.S. students (cf. Hypotheses 1a, 1b and 1c). Next, we present the results relevant to the major goal of this study, i.e., we test the basic assumption of the integrated theory of numerical development that fraction magnitude understanding is closely related to students' general mathematics achievement in all three countries (cf. Hypothesis 2).

\subsection{Differences among Countries on Fraction Tasks}

\subsubsection{Fraction number line estimation}


A 3 (Country: Belgium, China or U.S. $) \times 2$ (Grade: $6^{\text {th }}$ or $\left.8^{\text {th }}\right)$ ANOVA revealed gradeand country-specific differences in students' mean PAE on the 0-1 number line estimation task. As expected, $8^{\text {th }}$ graders more accurately estimated fraction magnitudes than $6^{\text {th }}$ graders, $P A E^{\prime} \mathrm{s}=7 \%$ and $12 \%, F(1,186)=11.79, p<.01$, partial eta $^{2}=.06$. Also as expected, Belgian, Chinese, and U.S. students' estimation accuracy differed, $F(2,186)=22.67, p<.01$, partial $e t a^{2}=.20$. Chinese students were much more accurate than U.S. students, mean $P A E=6 \%$ and $16 \%$. Belgian students' accuracy (mean PAE $=7 \%$ ) was as high as that of Chinese students and much higher than that of U.S. students. The non-significant Country $\times$ Grade interaction, $F(2,186)<1$, revealed that these country-specific differences in accuracy of estimates were present in both $6^{\text {th }}$ and $8^{\text {th }}$ grade (Table 2).

We observed similar results on 0-5 number lines. Sixth graders provided less accurate estimates than $8^{\text {th }}$ graders, mean $P A E=20 \%$ and $11 \%, F(1,186)=44.41, p<.01$, partial $e t a^{2}=.20$. On this more difficult number line task, Chinese students estimated more accurately than Belgian students, who, in turn, estimated more accurately than U.S. students, $P A E=9 \%, 16 \%$ and $23 \%, F(2,186)=34.46, p<.01$, partial $_{e t a^{2}}=.28$. Again, the Country $\times$ Grade interaction was not significant, $F(2,186)<1$.

-- Insert Table 2 about here --

\subsubsection{Fraction magnitude comparison}

A 3 (Country: Belgium, China or U.S. $) \times 2\left(\right.$ Grade: $6^{\text {th }}$ or $\left.8^{\text {th }}\right)$ ANOVA indicated that Chinese and Belgian students compared fraction magnitudes more accurately than U.S. students, $M^{\prime}$ 's $=82 \%, 82 \%$, and $71 \%, F(2,186)=3.58, p=.03$, partial eta $a^{2}=.04$; and that $8^{\text {th }}$ graders compared them more accurately than $6^{\text {th }}$ graders, $M$ 's $=85 \%$ and $72 \%$, $F(1,186)=11.59, p<.01$, partial $e t a^{2}=.06($ Table 2$)$. The Country $\times$ Grade interaction was not significant, $F(2,186)<1$.

\subsubsection{Fraction arithmetic}


A parallel Country $\times$ Grade ANOVA on fraction addition revealed main effects of Country, $F(2,186)=86.74, p<.01$, partial eta ${ }^{2}=.49$, and Grade, $F(1,186)=13.95, p<.01$, partial $e t a^{2}=.07$, and also a Country $\times$ Grade interaction, $F(2,186)=7.07, p<.01$, partial $e t a^{2}=.07$. The interaction reflected fraction addition in Belgium and China being similarly (highly) accurate in $6^{\text {th }}$ and $8^{\text {th }}$ grade, but performance in the U.S. starting out far lower and improving considerably between $6^{\text {th }}$ and $8^{\text {th }}$ grade (Table 2$)$.

For the fraction division task, a parallel Country $\times$ Grade ANOVA showed main effects of Country, $F(2,186)=82.01, p<.01$, partial eta ${ }^{2}=.48$, and Grade, $F(1,186)=13.95$, $p<.01$, partial $_{\text {eta }}{ }^{2}=.07$. Chinese students divided fractions more accurately than Belgian students, $M$ 's $=91 \%$ and $71 \%$; Belgian students divided more accurately than U.S. students, $M=22 \%$ correct; and $8^{\text {th }}$ graders divided more accurately than $6^{\text {th }}$ graders, $M$ 's $=75 \%$ and $53 \%$. The Country $\times$ Grade interaction just failed to reach significance, $F(2,186)=2.79$, $p=.06$, partial eta $a^{2}=.03$. Division accuracy increased between $6^{\text {th }}$ and $8^{\text {th }}$ grade for both Belgian and U.S. samples, whereas Chinese $6^{\text {th }}$ and $8^{\text {th }}$ graders were similarly accurate.

\subsubsection{Conclusion}

As expected, we observed clear differences among Belgian, Chinese and U.S. students in absolute levels of fraction knowledge. Consistent with Hypothesis 1a, Chinese students obtained higher scores on all fraction tasks than U.S. students; these results were observed in both $6^{\text {th }}$ and $8^{\text {th }}$ grade. Moreover, as indicated in Hypothesis 1c, Belgian students were consistently more accurate than their U.S. peers. The expected performance differences between Belgian and Chinese students, however, were only observed on the most difficult fraction tasks. Our findings revealed performance differences between the latter two groups of students on 0-5 number lines and fraction division, but contrary to Hypothesis $1 \mathrm{~b}$, similar differences were not present on number line and magnitude comparison with fractions from 01 or on fraction addition. 


\subsection{Relations among Magnitude Knowledge, Arithmetic, and Math Achievement}

To test our major hypothesis -- namely, that not only in the U.S. sample, but also in the Belgian and Chinese samples, fraction magnitude understanding is strongly related to general mathematics achievement (Hypothesis 2) -- we conducted correlational and hierarchical regression analyses. To increase the reliability of our measures and the statistical power of our tests, we averaged PAE's on the 0-1 and 0-5 number lines into a composite PAE, and we combined the addition and division percentages correct into a single arithmetic composite.

Table 3 presents correlations between number line estimation, magnitude comparison, arithmetic, and mathematics achievement scores. Although there were differences in the pattern of correlations across countries and grades, we found consistent strong correlations between number line estimation and mathematics achievement scores in all three countries. These correlations are consistent with the integrated theory's assumption that understanding of fraction magnitudes underlies general mathematics competence in this age range. Only for Chinese $8^{\text {th }}$ graders was this relation not present; its absence might be due to these students' very high performance on, and consequently small variance in, number line estimation.

The correlations shown in Table 3 point to two other important results that require further attention. First, although number line estimation and magnitude comparison are generally assumed to measure the same underlying construct, i.e., students' magnitude understanding, strong correlations between the two was only present for U.S. $6^{\text {th }}$ and $8^{\text {th }}$ graders and, to a lesser extent, Belgian $6^{\text {th }}$ graders. Moreover, magnitude comparison was correlated with general math achievement only in the U.S. samples. As discussed in more detail below, these variable relations raise questions about the reliability and validity of the magnitude comparison task with fractions.

Second, we found relatively weak, though sometimes significant, relations between number line estimation performances and fraction arithmetic scores (ranging from $r=-.23$ to 
$r=-.44)$. The relatively low correlations suggest that the two variables measure different competencies and that a common relation to IQ cannot explain the relation between the two variables and students' mathematics achievement test scores.

-- Insert Table 3 about here --

We next conducted hierarchical regression analyses to test whether a common relation to fraction arithmetic explained the relation between fraction magnitude understanding, as measured by number line PAE, and mathematics achievement scores. We evaluated the adequacy of four models for predicting mathematics achievement, namely (a) arithmetic accuracy (Model 1); (b) arithmetic accuracy + number line PAE (Model 2); (c) number line PAE (Model 3); (d) number line PAE + arithmetic accuracy (Model 4). Table 4 summarizes the results per model, country and grade.

-- Insert Table 4 about here --

When fraction arithmetic accuracy was first entered as a predictor of mathematics achievement, adding number line estimation considerably increased the explained variance in overall mathematics achievement in 5 of the 6 Country $\times$ Grade combinations (all except among Chinese $8^{\text {th }}$ graders). In contrast, when number line estimation PAE was first entered as a predictor of mathematics achievement scores, adding fraction arithmetic accuracy increased the explained variance in the U.S. sample only.

Taken together, these results support the major assumption of the integrated theory of numerical development, as expressed in Hypothesis 2: Fraction magnitude understanding, as measured with number line estimation tasks, predicts mathematics achievement, even when fraction arithmetic skill is statistically controlled. The data from the Belgian $6^{\text {th }}$ and $8^{\text {th }}$ graders, Chinese $6^{\text {th }}$ graders, and U.S. $8^{\text {th }}$ graders provided clear evidence for this assumption. The data from the U.S. $6^{\text {th }}$ graders were less straightforward, as fraction arithmetic competency and number line estimation were equally important for mathematics achievement. 
For Chinese $8^{\text {th }}$ graders, neither fraction magnitude understanding nor fraction arithmetic skill predicted mathematics achievement. This might be due to Chinese $8^{\text {th }}$ grade students' generally high performances, and (thus) small variance in performances, on the fraction tasks. Finally, the moderate correlations between fraction magnitude understanding and arithmetic among Belgian, Chinese and U.S. $6^{\text {th }}$ and $8^{\text {th }}$ graders, as well as the non-significant contribution of Belgian and Chinese students' fraction arithmetic skill when magnitude understanding was statistically controlled, argue against the possibility that the relations among fraction arithmetic, fraction magnitude knowledge and math achievement are only due to shared relations to IQ, which presumably would affect fraction arithmetic as well as fraction magnitude estimation. Hence, fraction magnitude understanding plays a pivotal role in mathematics development.

\section{Discussion}

The integrated theory of numerical development emphasizes that fractions play a key role in learning mathematics. Individual differences in the precision of fraction magnitude representations in later elementary school and middle school are hypothesized to play the same central role in mathematics achievement that differences in the precision of whole number magnitude representations play in earlier grades, when whole number magnitude representations are more variable. To test this assumption, we conducted a cross-cultural study in three countries that differ in the quality of teachers' mathematical knowledge, the instructional tools used for fraction instruction, and students' general math performances. Taking into account the results of previous work, we expected differences among countries in performance on fraction number line estimation, magnitude comparison, and arithmetic (cf. Hypotheses 1a, 1b, and 1c). By contrast, we did not expect country-specific differences in the relation between students' fraction magnitude understanding and their general math 
achievement scores, as this relation is assumed to reflect a general cognitive characteristic rather than a cultural or educational artefact (cf. Hypothesis 2).

\subsection{Performance Differences in Fraction Magnitude Understanding and Arithmetic}

In line with previous studies in the domain of fractions (e.g., Hill et al., 2005; Krauss et al., 2008; Mullis et al., 2008, 2012; Senk et al., 2012), the present study provided suggestive evidence for the influence of teachers' mathematical knowledge and instructional tools on fraction learning. Chinese students, instructed by teachers with rich mathematical knowledge and emphasizing number line interpretations of fractions, performed better on fraction magnitude understanding and fraction arithmetic tasks than U.S. students, who are often taught by teachers with shallower mathematical understanding (cf. Hypothesis 1a). Belgian students, taught by teachers whose mathematics knowledge seems to fall in between that of teachers in China and the U.S., made less errors than their U.S. peers on all fraction tasks (cf. Hypothesis 1c), but had more difficulty than their Chinese peers on the most difficult fraction tasks, i.e., 0-5 number line estimation and fraction division (cf. Hypothesis 1b). These findings suggest that instruction in both Belgium and China is strong enough for children to master the easier fraction tasks, but only the instruction in China is strong enough for children to learn the more difficult ones. However, since we were not able to conduct fine-grained analyses on the quality of fraction instruction provided to the students in our study, it is not clear whether this pattern is primarily due to Chinese teachers providing consistently superior instruction and Belgian teachers providing instruction that was good enough for students to master easier problems but not harder ones, or whether it is largely attributable to other cultural and educational differences, the amount of time spent on more difficult fraction problems, student motivation, or mastery of related mathematical concepts. Future studies are needed to test the viability of these potential explanations.

\subsection{Fraction Magnitude Understanding as a Key for General Math Development}


Of particular importance, the present study provided evidence for the pivotal role of fraction understanding in students' mathematics achievement across countries differing in cultural and educational practices (cf. Hypothesis 2). These results are in line with the major findings of previous studies with U.S. samples (see Bailey et al., 2012; Booth \& Newton, 2012; Siegler et al., 2012; Siegler et al., 2013; Siegler \& Pyke, 2013; Siegler et al., 2011) and thus indicate that prior findings on this topic are not limited to the U.S.

In Belgium, China, and the U.S., we observed consistent relations between students' fraction understanding and overall mathematics achievement. Moreover, in all three countries, fraction magnitude understanding was the best predictor of mathematics achievement scores, even after controlling for variation in fraction arithmetic skill. We did not observe this pattern of results in the oldest group of Chinese students, presumably due to ceiling effects in their knowledge of fraction magnitudes. Taken together, these results indicate that the relation between fraction magnitude understanding and mathematics achievement is not attributable to specifics of the U.S. educational system. Instead, the strong relation between fraction magnitude understanding and mathematics achievement can be interpreted as a general cognitive characteristic of all students, regardless of their specific cultural and educational background.

This conclusion does not imply that students' mathematics instructional histories have no influence on this relation. As indicated by the differences in the observed patterns for U.S. $6^{\text {th }}$ graders and Chinese $8^{\text {th }}$ graders, quality of instruction might strengthen or weaken the role of fraction understanding in mathematics learning. For instance, the importance of individual differences in fraction magnitude understanding might be diminished if all students receive strong mathematics instruction in which teachers maximize the learning opportunities for all students, including the weakest ones. Focused and well-designed intervention studies are 
needed to unravel the important but complex relation between the quality of fraction instruction and students' progress in the domain of fractions and beyond.

Finally, it might be argued that the observed relations between fraction magnitude understanding and general mathematical achievement are merely reflections of students' general intellectual abilities, as we did not control for this variable in the present study. However, both our results and the findings from other recent studies argue against this interpretation. First, the moderate correlations between fraction magnitude understanding and fraction arithmetic skill, and also the non-significant contribution of fraction arithmetic skill to general math achievement scores when magnitude understanding was statistically controlled, argue against the possibility that the relations among arithmetic, magnitude knowledge, and overall achievement that we observed in the present study were only due to shared relations to IQ. Moreover, recent empirical investigations on this topic have demonstrated that fraction understanding is strongly related to fraction arithmetic and mathematical achievement, even after statistically controlling for IQ, reading level, executive functioning, and knowledge of all four whole number operations (Bailey et al., in press; Siegler et al., 2012; Siegler \& Pyke, 2013). Notwithstanding these findings and arguments, future studies should take into account students' general intellectual capacities when analysing the pivotal role of fraction magnitude understanding in their further math development.

Future studies are also needed to test whether the integrated theory of numerical development applies not only to rational numbers but also to irrational numbers (i.e., numbers that cannot be expressed as common fractions, for example the square root of 2 and the number $\pi$ ). All real numbers, not just the rational numbers, can be compared, ordered, and interpreted as points on a number line (Bloch, 2011, p. 1). This suggests that a key step in understanding real numbers is the realization that not only whole numbers or rational numbers 
but in fact all real numbers have magnitudes that can be represented along a number line. To the best of our knowledge, this hypothesis has not been tested empirically so far.

\subsection{Number Line Estimation and Number Comparison as Assessments of Numerical}

\section{Understanding}

The present study also adds to recent discussions of relations between the tasks that are used to empirically investigate magnitude understanding (cf. Ebersbach, Luwel, \& Verschaffel, 2013; Sasanguie, Defever, Van den Bussche, \& Reynvoet, 2011). With whole numbers, both number line estimation and number comparison tasks correlate substantially with mathematical achievement and more specific mathematical skills in various countries and age groups (e.g., Booth \& Siegler, 2006; De Smedt, Verschaffel, \& Ghesquière, 2009; Holloway \& Ansari, 2008; Sasanguie, Göbel, Moll, Smets, \& Reynvoet, 2013; Schneider, Grabner, \& Paetsch, 2009; Schneider et al., 2008; Siegler \& Ramani, 2009). This demonstrates that both tasks reliably assess central aspects of mathematical competence. However, it has also been shown that versions of these tasks differing in surface structures and cognitive demands tap into partly different aspects of magnitude understanding and can yield, for example, different solution rates or different correlations with achievement measures (cf. De Smedt, Noël, Gilmore, \& Ansari, 2013; Gilmore et al., 2013; Huber, Moeller, \& Nuerk, 2013; Lyons, Ansari, \& Beilock, 2012; Sasanguie \& Reynvoet, 2013; Schneider et al., 2008; Vogel, Grabner, Schneider, Siegler, \& Ansari, 2013). Our results demonstrate that number line estimation and number comparison tap into partly different aspects of magnitude understanding, not only with whole numbers but also with fractions. Future empirical research is needed to show in greater detail how task demands moderate the outcomes and the reliabilities of different assessments of magnitude knowledge for both types of numbers.

\subsection{Instructional Implications}


The centrality of magnitude understanding for mathematical achievement has profound implications for teaching fractions. For whole numbers, it has been shown that simple feedback interventions (Opfer \& Siegler, 2007) and even numerical board games (Ramani \& Siegler, 2008), in which children map numbers onto space, can substantially improve children's magnitude understanding. These interventions can be implemented in classrooms easily and effectively (Ramani, Siegler, \& Hitti, 2012). The intervention effects are particularly strong for children from low-income households, who have fewer experiences in playing number games and have less numerical knowledge than their peers (Siegler, 2009). Improvements in magnitude understanding have positive causal influences on arithmetic learning (Booth \& Siegler, 2008; Siegler \& Ramani, 2009) and memory for numbers (Thompson \& Siegler, 2010).

Our correlational analyses suggest that similar interventions might be effective in the domain of fractions. Evidence in support of this hypothesis comes from two different intervention studies with elementary school children in the domain of fractions. First, the study of Gabriel and colleagues (2012) with $2924^{\text {th }}$ and $5^{\text {th }}$ graders who received differential instruction on fraction understanding for 10 weeks, two times a week, 30 minutes per session, demonstrated that learning activities based on the use of card games focusing on the representation and manipulation of fractions in terms of their magnitudes, considerably increased students' fraction magnitude understanding. Similar results were obtained in the study conducted by Fuchs and colleagues (2013), involving 259 at-risk $4^{\text {th }}$ graders receiving different interventions about fraction understanding and arithmetic for 12 weeks, three times a week, 30 minutes per session. The intervention, which put a greater emphasis on measurement and number line interpretations of fractions, was more effective than an alternative instructional approach, which emphasized part-whole interpretations of fractions. Children's increases in magnitude understanding mediated their increases in other outcome 
Running head: FRACTION UNDERSTANDING: THREE CONTINENTS 24

measures. However, the different interventions applied in the reported studies combined a variety of instructional techniques, learner activities, and fraction representations. Subsequent research will have to clarify if, when, how, and for whom interventions can improve magnitude understanding of fractions and whether these improvements transfer to fraction arithmetic and mathematical achievement. 
Running head: FRACTION UNDERSTANDING: THREE CONTINENTS 25

\section{Footnotes}

${ }^{1}$ It should be noted that knowledge acquisition, instruction, and cognitive development are closely intertwined both in real life and in the integrated theory of numerical development. Therefore, the word development in the latter theory's name should be understood in its broadest meaning, i.e., as integrating -- rather than excluding -- knowledge acquisition and instruction as important influences on people's numerical development. However, for readability reasons, the authors decided not to include all three sources of competence growth in the theory's name and refer to the, in the learning sciences, well-known and frequently used term development.

${ }^{2}$ We selected three countries that do not differ in the timing of fraction instruction. However, as suggested by one reviewer, it would be very interesting to explore the effectiveness of different timing of fraction and pre-algebra instruction on students' further math development in future investigations. 


\section{References}

Bailey, D. H., Hoard, M. K., Nugent, L., \& Geary, D. C. (2012). Competence with fractions predicts gains in mathematics achievement. Journal of Experimental Child Psychology, 113, 447-455. doi: 10.1016/j.jecp.2012.06.004

Bailey, D. H., Siegler, R. S., \& Geary, D. C. (2014). Early predictors of middle school fraction knowledge. Developmental Science, published on-line, 2-27-14. doi: $10.1111 /$ desc. 12155

Ball, D. L. (1990). The mathematical understandings that prospective teachers bring to teacher education. The Elementary School Journal, 90, 449-466. doi: 10.1086/461626

Bloch, E. D. (2011). The real numbers and real analysis. New York: Springer.

Booth, J. L.,\& Newton, K. J. (2012). Fractions: Could they really be the gatekeeper's doorman? Contemporary Educational Psychology, 37, 247-253. doi: 10.1016/j.cedpsych.2012.07.001

Booth, J. L., \& Siegler, R. S. (2006). Developmental and individual differences in pure numerical estimation. Developmental Psychology, 42, 189-201. doi: 10.1037/00121649.41.6.189

Booth, J. L., \& Siegler, R. S. (2008). Numerical magnitude representations influence arithmetic learning. Child Development, 79, 1016-1031. doi: 10.1111/j.14678624.2008.01173.x

Deloof, G. (2005). Leerlingvolgsysteem Wiskunde Toetsen 6: Basisboek [Learner Following System Mathematics, Tests Grade 6: Manual]. Antwerpen, Belgium: Garant.

Depaepe, F., Torbeyns, J., Vermeersch, N., Janssens, D., Janssen, R., Kelchtermans, G., Verschaffel, L., \& Van Dooren, W. (2013). Prospective elementary and lower secondary teachers' content and pedagogical content knowledge in the rational number domain. Manuscript submitted for publication. 
De Smedt, B., Noël, M.-P., Gilmore, C., \& Ansari, D. (2013). The relationship between symbolic and non-symbolic numerical magnitude processing and the typical and atypical development of mathematics: a review of evidence from brain and behavior. Trends in Neuroscience and Education, 2, 48-55.

De Smedt, B., Verschaffel, L., \& Ghesquière, P. (2009). The predictive value of numerical magnitude comparison for individual differences in mathematics achievement. Journal of Experimental Child Psychology, 103, 469-479. doi: 10.1016/j.jecp.2009.01.010

DeWolf, M., \& Vosniadou, S. (this issue). The representation of fraction magnitudes and the whole number bias reconsidered.

Ebersbach, M., Luwel, K., \& Verschaffel, L. (2013). Comparing apples and pears in studies on magnitude estimations. Frontiers in Psychology, 4:332, doi:10.3389/fpsyg.2013.00332.

Fuchs, L. S., Schumacher, R. F., Long, J., Namkung, J., Hamlett, C. L., Cirino, P. T., Jordan, N. C., Siegler, R. S., Gersten, R., \& Changas, P. (2013). Improving at-risk learners' understanding of fractions. Journal of Educational Psychology, 105, 683-700. doi: $10.1037 / \mathrm{a} 0032446$

Gabriel, F., Coché, F., Szucs, D., Carette, V., Rey, B., \& Content, A. (2012). Developing children's understanding of fractions: an intervention study. Mind, Brain, and Education, 6, 137-146. doi:10.1111/j.1751-228X.2012.01149.x

Geary, D. C. (2006). Development of mathematical understanding. In W. Damon, et al. (Eds.), Handbook of Child Psychology: Cognition, Perception, and Language (Vol. 2, pp. 777-810). Hoboken, NH: Wiley. doi: 10.1002/9780470147658.chpsy0218

Gielen, S., Van Dessel, K., De Meyst, M., Beringhs, S., Crynen, M., Luyten, B., \& Janssen, R. (2010). Peiling wiskunde in de eerste graad van het secundair onderwijs A-stroom- 
Eindrapport [Mathematics assessment in the first grade of secondary education, A-stream - Final report]. K.U. Leuven, Centrum voor Onderwijseffectiviteit en -evaluatie, Leuven.

Gilmore, C. K., Attridge, N., Clayton, S., Cragg, L., Johnson, S., Marlow, N., Simms, V., \& Inglis, M. (2013). Individual differences in inhibitory control, not non-verbal number acuity, correlate with mathematics achievement. PLOS One, 8(6), doi: 10.1371/journal.pone.0067374

Hattie, J. (2009). Visible learning. A synthesis of over 800 meta-analyses relating to achievement. London: Routledge.

Hill, H. C., Rowan, B., \& Ball, D. (2005). Effects of teachers' mathematical knowledge for teaching on student achievement. American Educational Research Journal, 42, 371-406. doi: 10.3102/00028312042002371

Holloway, I., \& Ansari, D. (2008). Domain-specific and domain-general changes in children's development of number comparison. Developmental Science, 11, 644-649. doi: 10.1111/j.1467-7687.2008.00712.x

Huber, S., Moeller, K., \& Nuerk, H.-C. (2013). Dissociating number line estimations from underlying numerical representations. The Quarterly Journal of Experimental Psychology, published on-line, 10-16-13. doi: 10.1080/17470218.2013.838974

Krauss, S., Brunner, M., Kunter, M., Baumert, J., Blum, W., Neubrand, M., \& Jordan, A. (2008). Pedagogical content knowledge and content knowledge of secondary mathematics teachers. Journal of Educational Psychology, 100, 716-725. doi: 10.1037/00220663.100.3.716

Leslie, A. M., Gelman, R., \& Gallistel, C. R. (2008). The generative basis of natural number concepts. Trends in Cognitive Sciences, 12, 213-218. doi: 10.1016/j.tics.2008.03.004 
Lyons, I. M., Ansari, D., \& Beilock, S. L. (2012). Symbolic estrangement: Evidence against a strong association between numerical symbols and the quantities they represent. Journal of Experimental Psychology: General, 141, 635-641. doi: 10.1037/a0027248

Ma, L. (1999). Knowing and teaching elementary mathematics: Teachers understanding of fundamental mathematics in China and the United States. Mahwah, NJ: Erlbaum.

Merenluoto, K., \& Lehtinen, E. (2002). Conceptual change in mathematics: Understanding the real numbers. In M. Limón \& L. Mason (Eds.), Reconsidering conceptual change. Issues in theory and practice (pp. 233-258). Dordrecht: Kluwer Academic Publishers. doi: 10.1007/0-306-47637-1_13

Mullis, I. V. S., Martin, M. O., \& Foy, P. (with Olson, J. F., Preuschoff, C., Erberber, E., Arora, A., \& Galia, J. (2008). TIMSS 2007 International Mathematics Report: Findings from IEA's Trends in International Mathematics and Science Study at the Fourth and Eighth Grades. Chestnut Hill, MA: TIMSS \& PIRLS International Study Center, Boston College.

Mullis, I. V. S., Martin, M. O., Foy, P., \& Arora, A. (2012). TIMSS 2011 International Results in Mathematics. Chestnut Hill, MA: TIMSS \& PIRLS International Study Center, Boston College.

Ni, Y., \& Zhou, Y.-D. (2005). Teaching and learning fraction and rational numbers: The origins and implications of whole number bias. Educational Psychologist, 40, 27-52. doi: 10.1207/s15326985ep4001_3

Opfer, J. E., \& Siegler, R. S. (2007). Representational change and children's numerical estimation. Cognitive Psychology, 55, 169-195. doi: 10.1016/j.cogpsych.2006.09.002

Ramani, G. B., \& Siegler, R. S. (2008). Promoting broad and stable improvements in lowincome children's numerical knowledge through playing number board games. Child Development, 79, 375-394. doi:10.1111/j.1467-8624.2007.01131.x 
Ramani, G. B., Siegler, R. S., \& Hitti, A. (2012). Taking it to the classroom: Number board games as a small group learning activity. Journal of Educational Psychology, 104, 661672. doi: $10.1037 / \mathrm{a} 0028995$

Sasanguie, D., Defever, E., Van den Bussche, E., \& Reynvoet, B. (2011). The reliability of and the relation between non-symbolic numerical distance effects in comparison, samedifferent judgments and priming. Acta Psychologica, 136, 73-80. doi: 10.1016/j.actpsy.2010.10.004

Sasanguie, D., Göbel, S., Moll, K., Smets, K., \& Reynvoet, B. (2013). Acuity of the approximate number sense, symbolic number comparison or mapping numbers onto space: what underlies mathematics achievement? Journal of Experimental Child Psychology, 114, 418-431. doi: 10.1016/j.jecp.2012.10.012

Sasanguie, D., \& Reynvoet, B. (2013). Number comparison and number line estimation rely on different mechanisms. Psychologica Belgica, 53, 17-35.

Schneider, M., Grabner, R. H., \& Paetsch, J. (2009). Mental number line, number line estimation, and mathematical achievement: their interrelations in grades 5 and 6. Journal of Educational Psychology, 101, 359-372. doi: 10.1037/a0013840

Schneider, M., Heine, A., Thaler, V., Torbeyns, J., De Smedt, B., Verschaffel, L., et al. (2008). A validation of eye movements as a measure of elementary school children's developing number sense. Cognitive Development, 23, 424-437. doi: 10.1016/j.cogdev.2008.07.002

Senk, S. L., Tatto, M. T., Reckase, M., Rowley, G., Peck, R., \& Bankov, K. (2012). Knowledge of future primary teachers for teaching mathematics: An international comparative study. ZDM Mathematics Education, 44, 307-324. doi: 10.1007/s11858-0120400-7 
Siegler, R. S. (2009). Improving the numerical understanding of children from low-income families. Child Development Perspectives, 3, 118-124. doi:10.1111/j.17508606.2009.00090.x

Siegler, R. S., Duncan, G. J., Davis-Kean, P. E., Duckworth, K., Claessens, A., Engel, M., Susperreguy, M. I., \& Chen, M. (2012). Early predictors of high school mathematics achievement. Psychological Science, 23, 691-697. doi: 10.1177/0956797612440101

Siegler, R. S., Fazio, L. K., Bailey, D. H., \& Zhou, X. (2013). Fractions: The new frontier for theories of numerical development. Trends in Cognitive Science, 17, 13-19. doi: 10.1016/j.tics.2012.11.004

Siegler, R. S., \& Pyke, A. A. (2013). Developmental and individual differences in understanding of fractions. Developmental Psychology, 49, 1994-2004. doi: $10.1037 / \mathrm{a} 0031200$

Siegler, R. S., \& Ramani, G. B. (2009). Playing linear number board games - but not circular ones - improves low-income preschoolers' numerical understanding. Journal of Educational Psychology, 101, 545-560. doi: 10.1037/a0014239

Siegler, R. S., Thompson, C. A., \& Schneider, M. (2011). An integrated theory of whole number and fractions development. Cognitive Psychology, 62, 273-296. doi: 10.1016/j.cogpsych.2011.03.001

Stafylidou, S., \& Vosniadou, S. (2004). The development of students' understanding of the numerical value of fractions. Learning and Instruction, 14, 503-518. doi: 10.1016/j.learninstruc.2004.06.015

Stevenson, H. W., \& Stigler, J. W. (1992). The learning gap. Why our schools are failing and what we can learn from Japanese and Chinese education. New York: Free Press. 
Thompson, C. A., \& Siegler, R. S. (2010). Linear numerical magnitude representations aid children's memory for numbers. Psychological Science, 21, 1274-1281. doi: $10.1177 / 0956797610378309$

Vamvakoussi, X., \& Vosniadou, S. (2010). How many decimals are there between two fractions? Aspects of secondary school students' understanding of rational numbers and their notation. Cognition and Instruction, 28, 181-209. doi:10.1080/07370001003676603

Vogel, S. E., Grabner, R. H., Schneider, M., Siegler, R. S., \& Ansari, D. (2013). Overlapping and distinct brain regions involved in estimating the spatial position of numerical and non-numerical magnitudes: An fMRI study. Neuropsychologia, 51, 979-989. doi: 10.1016/j.neuropsychologia.2013.02.001

Verschaffel, L., Janssens, S., \& Janssen, R. (2005). The development of mathematical competence in Flemish preservice elementary school teachers. Teaching and Teacher Education, 21, 49-63. doi: 10.1016/j.tate.2004.11.005

Wang, J., \& Lin, E. (2009). A meta-analysis of comparative studies on Chinese and US students' mathematics performance: Implications for mathematics education reform and research. Educational Research Review, 4, 177-195. doi:10.1016/j.edurev.2009.06.003

Wu, H. (2001). How to prepare students for algebra. American Educator, 25(2), 10-17.

Wu, H. (2009). What's sophisticated about elementary mathematics? American Educator, $33(3), 4-14$.

Wynn, K. (2002). Do infants have numerical expectations or just perceptual preferences? Developmental Science, 2, 207-209. doi: 10.1111/1467-7687.00221_3 
Running head: FRACTION UNDERSTANDING: THREE CONTINENTS 33

Table 1.

Number, gender and age of participants per country and grade

\begin{tabular}{lcccccc}
\hline Country & Grade & $n$ & Gender $^{\mathrm{a}}$ & & \multicolumn{2}{l}{ Age (in years) } \\
& & & $m$ & $f$ & $M$ & $S D$ \\
\hline Belgium & 6 & 30 & 13 & 17 & 11.2 & 0.5 \\
& 8 & 34 & 11 & 22 & 13.3 & 0.5 \\
\hline China & 6 & 30 & 22 & 8 & 12.3 & 0.6 \\
& 8 & 39 & 19 & 20 & 14.3 & 0.7 \\
\hline U.S. & 6 & 31 & 19 & 12 & 11.4 & 0.6 \\
& 8 & 23 & 11 & 12 & 13.2 & 0.4 \\
\hline
\end{tabular}

${ }^{\mathrm{a}}$ Gender information is missing for 1 Belgian $8^{\text {th }}$ grader. 
Running head: FRACTION UNDERSTANDING: THREE CONTINENTS 34

Table 2 .

Performances on fraction tasks per country and grade (SD)

\begin{tabular}{lllllll}
\hline Country & Grade & Number line 0-1 & Number line 0-5 & Comparison accuracy & Addition accuracy & Division accuracy \\
& & PAE & PAE & & \\
\hline Belgium & 6 & $9.38(8.01)$ & $20.08(11.28)$ & $76.67(21.04)$ & $79.17(24.64)$ & $56.67(42.00)$ \\
& 8 & $5.05(4.34)$ & $12.20(6.37)$ & $86.52(21.02)$ & $86.76(20.63)$ & $84.56(26.12)$ \\
& 6 & $9.82(8.05)$ & $13.73(7.68)$ & $74.17(33.93)$ & $90.83(15.37)$ & $89.17(26.00)$ \\
\hline China & 8 & $3.88(2.05)$ & $5.97(2.97)$ & $88.46(19.37)$ & $91.03(14.61)$ & $92.95(20.64)$ \\
& 6 & $17.38(12.88)$ & $26.23(9.99)$ & $65.86(22.81)$ & $17.74(30.41)$ & $14.52(21.19)$ \\
\hline U.S. & 8 & $14.93(11.79)$ & $17.97(8.85)$ & $76.81(17.58)$ & $51.09(40.93)$ & $31.52(38.60)$ \\
\hline
\end{tabular}


Table 3.

Correlations between fraction tasks and general math achievement score per country and grade

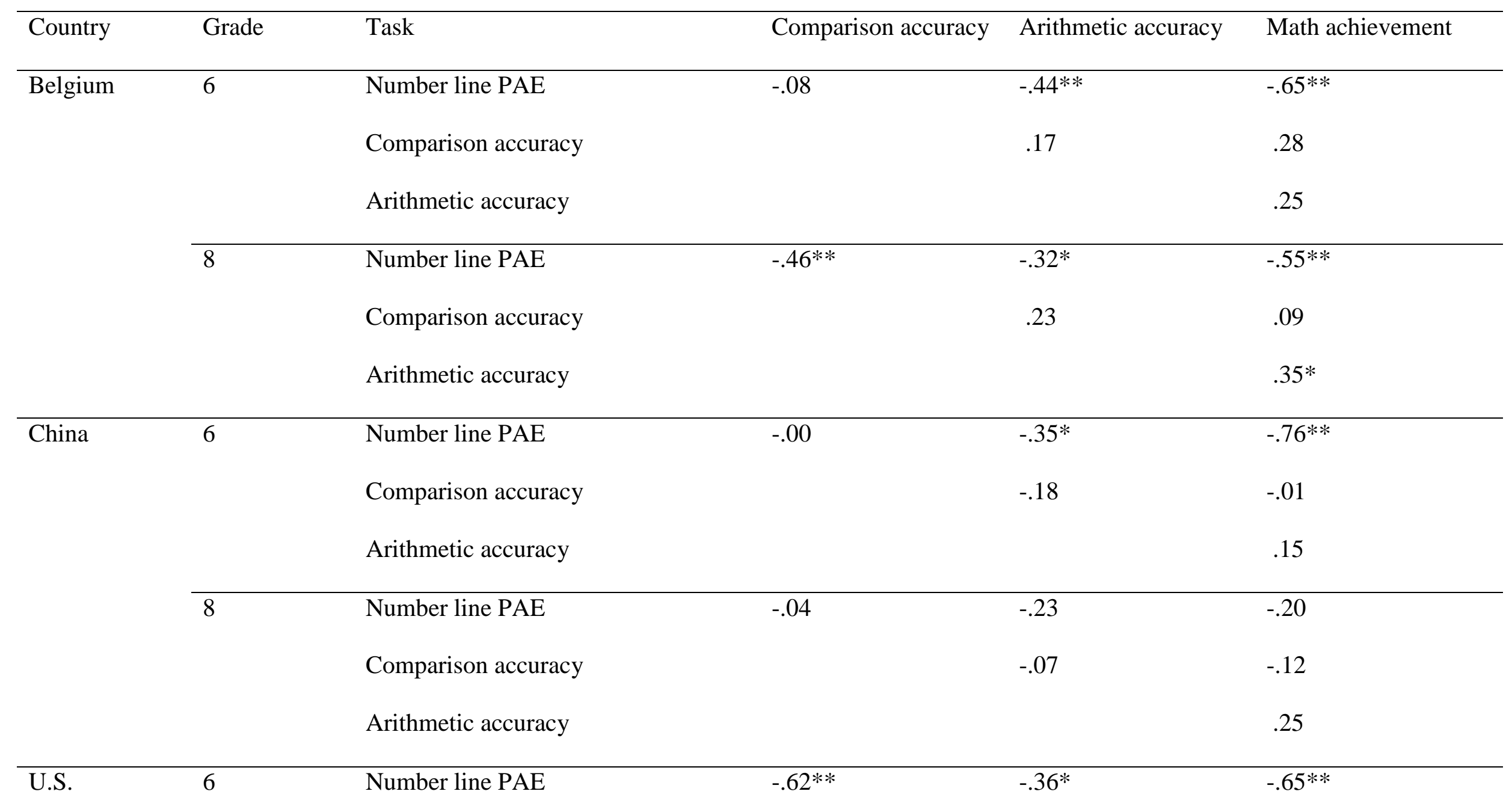


Running head: FRACTION UNDERSTANDING: THREE CONTINENTS 36

$\begin{array}{lll}\text { Comparison accuracy } & .36^{*} & .57 * *\end{array}$

$\begin{array}{ll}\text { Arithmetic accuracy } & .64^{* *}\end{array}$

$8 \quad$ Number line PAE

$-.78^{* *}$

$-.31$

$-.76^{* *}$

Comparison accuracy

.24

$.60 * *$

Arithmetic accuracy

$.53 * *$

$* p<.05 ; * * p<.01$ 
Running head: FRACTION UNDERSTANDING: THREE CONTINENTS 37

Table 4.

Hierarchical regression analyses: adjusted $r^{2}, F$ - and $\beta$-values per model, country and grade

\begin{tabular}{|c|c|c|c|c|c|c|}
\hline Country & Grade & Model & Predictor & Adjusted $\mathrm{r}^{2}$ & $\mathrm{~F}$ & $\beta$ \\
\hline \multirow[t]{22}{*}{ Belgium } & 6 & 1 & Arithmetic & .03 & 1.79 & .25 \\
\hline & & & accuracy & & & \\
\hline & & 2 & 1_Arithmetic & .38 & $9.89 * *$ & -.05 \\
\hline & & & accuracy & & & \\
\hline & & & 2_Number line & & & $-.67 * *$ \\
\hline & & & PAE & & & \\
\hline & & 3 & Number line PAE & .40 & $20.34 * *$ & $-.65 * *$ \\
\hline & & 4 & 1_Number line & .38 & $9.89 * *$ & $-.67 * *$ \\
\hline & & & PAE & & & \\
\hline & & & 2_Arithmetic & & & -.05 \\
\hline & & & accuracy & & & \\
\hline & 8 & 1 & Arithmetic & .10 & $4.45^{*}$ & $.35^{*}$ \\
\hline & & & accuracy & & & \\
\hline & & 2 & 1_Arithmetic & .29 & $7.64 * *$ & .21 \\
\hline & & & accuracy & & & \\
\hline & & & 2_Number line & & & $-.48 * *$ \\
\hline & & & PAE & & & \\
\hline & & 3 & Number line PAE & .28 & $13.18 * *$ & $-.55 * *$ \\
\hline & & 4 & 1_Number line & .29 & $7.64 * *$ & $-.48 * *$ \\
\hline & & & PAE & & & \\
\hline & & & 2_Arithmetic & & & .21 \\
\hline & & & accuracy & & & \\
\hline
\end{tabular}


Running head: FRACTION UNDERSTANDING: THREE CONTINENTS 38

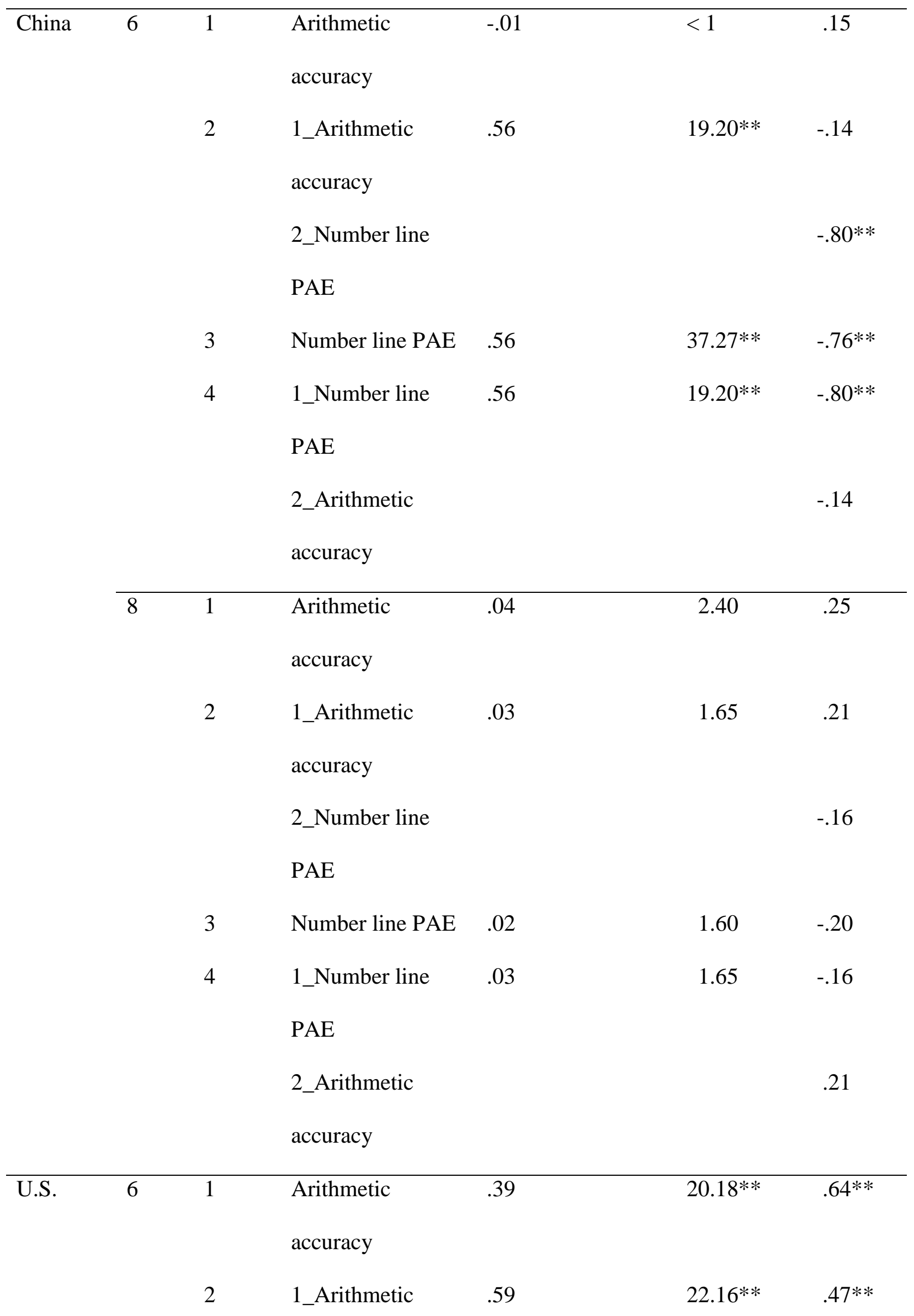


Running head: FRACTION UNDERSTANDING: THREE CONTINENTS 39

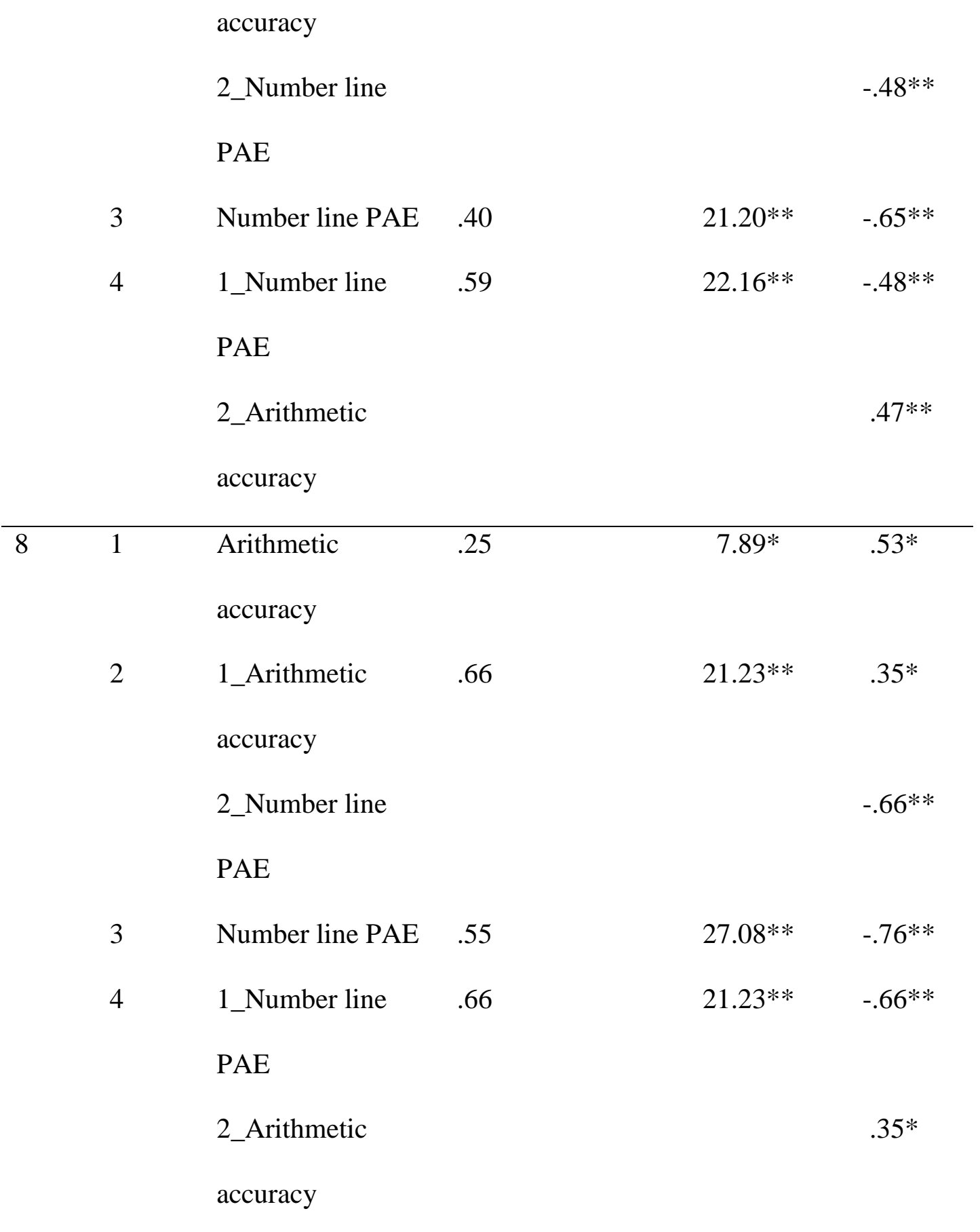

$* p<.05 ; * * p<.01$ 
Running head: FRACTION UNDERSTANDING: THREE CONTINENTS 40

\section{Acknowledgements}

This research was partially supported by Grant GOA 2012/10 "Number sense: Analysis and improvement" from the Research Fund KU Leuven, Belgium (Joke Torbeyns); by Grant Schn1097/2-1 of the German Research Foundation (DFG) (Michael Schneider); by Grant 30970909 from the National Natural Science Foundation of China (Ziqiang Xin); by U.S. Department of Education Grant R305H050035 and by the Siegler Center for Innovative Learning at Beijing Normal University (Robert S. Siegler). 